\title{
Grandparents' Childcare and Female Labor Force Participation
}

\author{
Josefina Posadas ${ }^{1}$ and Marian Vidal-Fernandez ${ }^{2^{*}}$
}

\author{
* Correspondence: \\ m.vidal-fernandez@unsw.edu.au \\ ${ }^{2}$ University of New South Wales \\ and IZA, ASB building, 2052, \\ Sydney, Australia \\ Full list of author information is \\ available at the end of the article
}

\begin{abstract}
In the United States, approximately 20\% of employed mothers with children under 5 use grandparents as their primary source of childcare. Using the National

Longitudinal Survey of Youth 1979 (NLSY79), we investigate whether the availability of this source of childcare has a causal effect on mother's labor force participation. We compare Ordinary Least Squares O(OLS), women's Fixed Effects (FE) and Instrumental Variables (IV) estimates. We find that OLS estimates overestimate the effect of grandparental childcare on young mothers' labor force participation and are not significantly different from IV estimates. In our preferred specification, FE, we find that the availability of grandparental childcare significantly increases mothers' labor force participation by 9 percentage points and that this effect is largely driven by minority, single or never married mothers. Our findings suggest that policies that raise retirement ages might increase older cohorts' labor participation rates at the expense of young women's through childcare availability.

JEL codes: J2; 13 .

Keywords: Maternal labor force participation; Grandparents; Childcare
\end{abstract}

\section{Introduction}

Despite the large increase in female labor force participation in the last few decades in the U.S ${ }^{1}$ and other developed countries, women still often face a choice between working and childrearing. While a vast literature shows that the availability of low-priced formal childcare increases labor force engagement of young women with children ${ }^{2}$, there is less evidence on the role that informal childcare plays in increasing mothers' labor force participation.

In the U.S., formal childcare costs have been increasing over time (Smith 2000, 2002) and grandparents, particularly maternal grandmothers, have become a prevalent childcare option arguably due to its flexibility and affordability (Presser, 1989). Figure 1 shows how the proportion of employed mothers with children younger than five years of age using grandparents as their primary source of childcare has steadily increased from 15 to 20 percent in the last two decades.

In Europe, these figures might be even higher. For example, Bien et al. (2006) find that in Germany, a third of respondents with children depend on grandparents for childcare and in Spain, almost 30\% of employed mothers between 25 and 44 rely on their parents or in-laws for child care support ${ }^{3}$.

At the same time, governments have been actively pursuing polices that increase retirement ages. However, if young women are less likely to work when they do not have

\section{Springer}

(C) 2013 Posadas and Vidal-Fernandez; licensee Springer. This is an Open Access article distributed under the terms of the Creative Commons Attribution License (http://creativecommons.org/licenses/by/2.0), which permits unrestricted use, distribution, and reproduction in any medium, provided the original work is properly cited. 


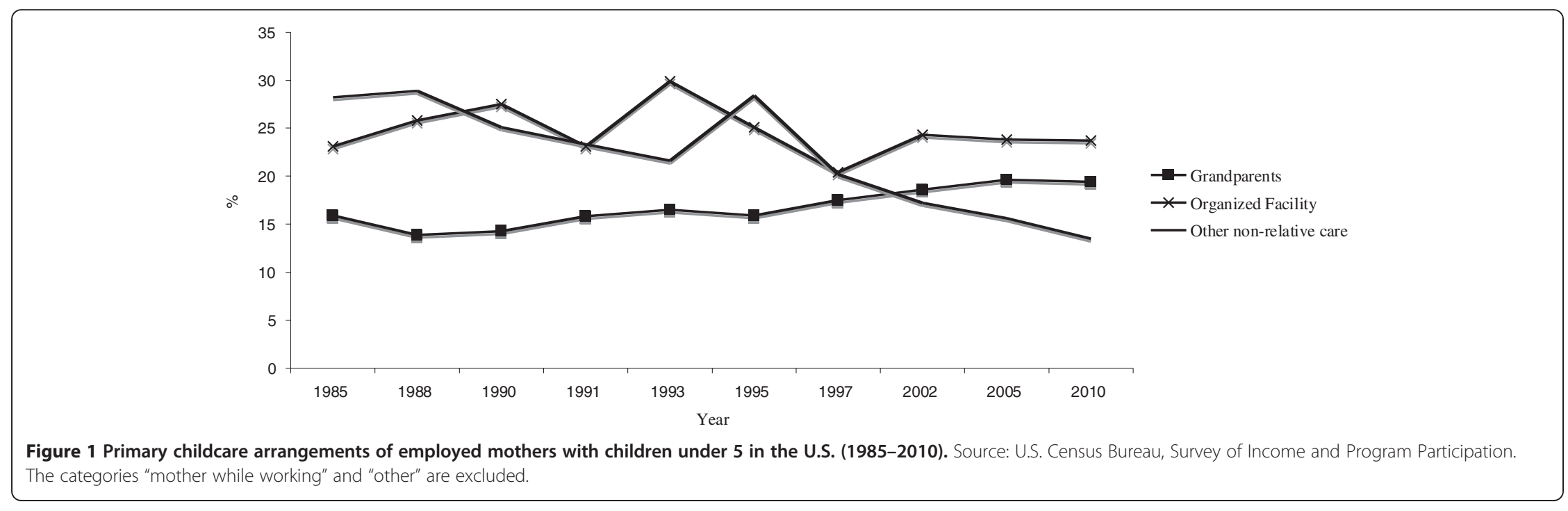


access to grandparental childcare, pension reforms encouraging a delay in retirement might increase tax revenues from older cohorts at the expense of younger women's contributions. Moreover, if retirement policies lead to short-term increases in older cohort's labor force participation rates yet younger women stay out of the labor force for a long period, then the net effect of these policies can be counterproductive and reduce tax revenues. In fact, Mosisa and Hipple (2006) find that while female labor force participation of women aged 55 and over has increased in the U.S. in the last decade, participation rates have decreased for younger cohorts of women.

Given the significant proportion of grandparents providing childcare and the increasing interest in policies encouraging a delay in retirement ages, it seems worth exploring to what extent young women's labor force participation depends on grandparents' childcare availability.

Identifying a causal effect of grandparental childcare on mother's labor force participation is challenging for at least two reasons. First, unobserved factors that affect both the availability of grandparental childcare and mothers' employment decisions will bias OLS estimates. For example, if we do not take into account that career-oriented women are more likely to leave their hometown to take a job offer, making them also less able to use grandparents for childcare, OLS estimates will underestimate the effect of grandparental childcare on young mothers' labor force participation. The second identification challenge is reverse causality or endogeneity. Mothers and grandmothers might take simultaneous labor force and childcare decisions. For instance, if grandparents offer themselves as an alternative to formal childcare once young women have already decided to engage in the labor force, OLS will overestimate the effect of grandparent's childcare on mother's labor force participation.

Using the National Longitudinal Survey of Youth 1979 (NLSY79), we tackle the first challenge by (1) controlling by a range of family background characteristics, and (2) using women's Fixed Effects (FE) to control for family heterogeneity. We attempt to resolve reverse causality by using maternal grandmother's death as an instrument for the availability of grandparental childcare. We find that OLS estimates are likely to overestimate the effect of grandparental childcare on young women's labor force participation and are not significantly different from IV estimates. Our most conservative estimate -women's Fixed Effects- suggests that having access to grandparental childcare in the U.S. leads to a statistically significant 9 percent increase in mother's labor force participation.

We discuss the possible caveats of these approaches throughout and argue that because grandparental childcare is a more affordable option than formal childcare (Presser, 1989), we should expect a larger effect for mothers who are more price-sensitive or in need of long childcare hours. Exploring heterogeneous effects we find that, indeed, the effect is larger for Black, Hispanic, and single or never married mothers.

The rest of the paper is organized as follows: Section 2 revises the existing literature and Section 3 discusses the relationship between grandparental childcare and mother's labor force participation. Section 4 describes the data and Sections 5 and 6 discuss the results. Section 7 concludes.

\section{Literature review}

A large body of literature has shown that there is a strong link between grandparental childcare and mother's labor force participation ${ }^{4}$. Nonetheless, there have been very 
few attempts to establish a causal effect of the availability of grandparental childcare on female labor force participation. For example, using the NLSY79, Leibowitz et al. (1992) find a marginally significant and positive correlation between mother's labor force participation and having a grandmother living in the household. The authors argue that the variable "grandmother living in the household" proxies for grandparental childcare, which induces not only measurement error, but also omitted variable bias. For example, in the U.S. where healthcare costs are relatively high, women with sick mothers might have to take care of them at home as well as to work to pay for medical bills, which would overestimate the effect of grandparental childcare on mother's labor force participation.

Two other studies confirm a strong relationship between grandparents' geographical proximity and mother's labor force participation in Europe. Del Boca (2002) and Del Boca et al. (2005) find that in Italy, having a grandmother living near the household and being in good health increases the probability of being in the labor market for mothers of children under five. Another related and more recent paper by Albuquerque and Passos (2010) uses the European Social Survey (ESS) to show that mothers with children under 13 who have grandparents that provide childcare are 12.5 percent more likely to work. The first caveat of these papers (except from Albuquerque and Passos, 2010) is that their data does not have childcare information and therefore it does not allow them to directly test whether the potential channel of the effect of family distance on young women's labor force participation is actually childcare. Moreover, estimates are likely to be biased due to heterogeneity and reverse causality or joint decisionmaking.

Heterogeneity is a threat to identification because it is hard to defend that young mothers who move away from their hometown are comparable to those staying closer to their families. For example, in the U.S., a teenage mother might move in with her family to get childcare and financial help, whereas a well educated woman who moves away from home to attend college is going to be less likely to have their parents available for childcare later on. Given the evidence of positive selection into the labor force for women (Olivetti and Petrongolo, 2008), we should also expect the latter group of women will be more likely to engage in the labor force than the former, biasing the estimates of the effect of grandparents' childcare on young women's labor force participation downwards.

With regards to endogeneity, grandparents might decide to live close to their labor active daughters to offer themselves as childcare providers because they do not want their grandchildren to attend a formal childcare facility. Thus, the positive relationship between grandparents' proximity (or childcare) and mother's labor force participation in this case will be spurious.

Despite the aforementioned identification challenges, this topic is increasingly attracting the attention of researchers, and two other working papers have theoretically modeled the relationship between childcare choices and joint labor force participation of mothers and daughters. The first by Zamarro (2011) uses the Survey of Health, Aging and Retirement in Europe (SHARE) to estimate a joint mother-grandmother labor force participation model and finds that grandparental childcare positively affects mother's labor force participation but only in the Netherlands and Greece. The author's identification strategy relies on the assumption that unobserved characteristics related 
to labor force participation decisions of mothers and grandmothers are uncorrelated. However, it seems natural to think that the degree of labor force attachment can be transmitted from grandmothers to mothers (Farré and Vella, 2013).

The second study by Garcia-Moran and Kuehn (2012) employs an overlapping generation model that incorporates geographical proximity between mothers and grandmothers and mother's fertility, childcare and labor force participation choices. Using the German Socio-Economic Panel (G-SOEP) the authors find that women who reside close to parents or in-laws are more likely to have children and to hold a regular job. Nonetheless, as acknowledged by the authors, they do not use any source of exogeneity to establish causal relationships between geographical proximity, grandparental childcare provision, and young mothers' labor force participation.

To our knowledge, there are only two other papers using exogenous variation of grandparents' availability to identify a causal link between grandparental childcare and young mother's labor force participation. Maurer-Fazio et al. (2011) find that in China, women between 25 to 50 years old who live with their parents or in-laws are 12 percent more likely to participate in the labor market. In their most compelling specifications, the set of instruments used to predict grandparental cohabitation are: the percentage of households in the county who have co-resident parents and/or parentsin-law and co-residents older than age 70, woman's age, husband's age, a set of interactions between the woman's age and her husband's age with higher order terms, and a full set of provincial dummies. Nonetheless, there is little discussion about whether each of these instruments satisfies the exclusion restriction and to what extent the results are robust to the choice of subsets of those instruments.

More recently, using the U.S. Census, Compton and Pollak (2013) find that the probability of employment increases 4 to 10 percentage points for young married women with young children if they live in the same state as their mothers or mothers in-law. As previously discussed, the main concern of this approach is that geographic location is not random. In a more compelling set of estimates, they use the subsample of military wives for whom distance to family is likely to be exogenous, and find similar magnitudes but noisier estimates. Finally, they support their results by showing no effect of distance on mother's labor force participation for women without childcare needs, i.e. unmarried and women without young children.

As with most of previous studies, the two aforementioned papers argue that the effect of co-residence or distance to grandparents on mother's labor force participation is through childcare provision. However, they both use census data, which does not contain information on grandparental childcare to directly test this hypothesis.

Our paper uses an alternative dataset and a range of identification strategies to provide direct evidence on the effect of grandparental childcare on mother's labor force participation. We use family FE estimates and maternal grandparent's death as an instrument of grandparental childcare to measure effects on mother's labor force participation. Our work is therefore also closely related to another stream of the literature that exploits parents' death (grandparents in our case) as a plausibly exogenous instrument to predict living in a single-headed household (Lang and Zargosky, 2001) or being an informal care provider to the elderly (an example is Coe and Van Houtven, 2009).

The contribution of our paper is two-fold. First, the richness of our data allows us to directly measure the relationship between young women's labor force participation and 
grandparents' childcare, use an extended set of background variables to explore heterogeneous effects, and undergo an extended set of robustness checks. Second, as far as we know, this is the first paper to use a family FE model to account for all possible sources of time-invariant heterogeneity together with an IV approach to complement the FE results and alleviate reverse causality concerns.

\section{Grandmother's status, childcare and mother's labor force participation}

To study the effect of grandparent's childcare on mother's labor force participation we aim to estimate the following equation:

$$
M L F P_{i t}=\alpha+\beta G P C_{i t}+\gamma X_{i t}+F_{i}+T_{t}+\varepsilon_{i t},
$$

where $i$ denotes individual and $t$ survey year. MLFP stands for maternal labor force participation (one if employed or unemployed and zero if out of the labor force). The vector $X$ includes the following individual-level variables: score on the Armed Forces Qualification Test (AFQT), age, age squared, number of children, real household income (not including mother's), a set of dummies equal to one if either he daughter lived in a household in which any member had a library card when she was 14 years old or she lived in an urban area in 1979, and race, marital status, living in an urban area, educational attainment, teenage motherhood, and region dummies. $F$ are women's Fixed Effects. All models are weighted to account for oversampling of minorities ${ }^{5}$ and errors are clustered at the family level.

Our variable of interest, GPC, is equal to one if besides the mother, either the primary, secondary, or tertiary childcare arrangement for any child between the ages of $0-3$ is a grandparent (maternal or paternal). As we briefly discussed in previous sections, the OLS estimate of our coefficient of interest $\beta$ is likely to be biased due to reverse causality and/or family heterogeneity.

For example, if an already employed woman is offered childcare by grandparents because they do not want leave children in formal childcare, OLS estimates will capture a positive but spurious relationship between grandparental childcare and mother's labor force participation.

Alternatively, women who cannot afford formal childcare might ask for childcare help from parents or in-laws. Because women from disadvantaged background are less likely to work (Mulligan and Rubinstein, 2008) and more likely to use grandparental care because it is more affordable than formal childcare (Presser 1989), we should expect that omitting relevant background characteristics in OLS models will underestimate the effect of grandparental childcare on mother's labor force participation.

We tackle this challenge in two ways. First, we use FE models that account for $F$ in the equation above, that is, time-invariant family heterogeneity such as young women's career motivations, genetic and socio-economic characteristics. While OLS estimates are subject to bias due to unobserved characteristics linked to the choice of childcare and young women's labor force participation, FE estimates will be also biased if there exist further time-varying characteristics linked to both young women's labor force participation and grandparental childcare that we are not accounting for. For instance, changes in family members' health status can potentially bias FE estimates of grandparents' childcare on young women's labor force participation in several ways. On the one hand, if grandparents stop taking care of grandchildren because their health status 
deteriorates, young women can either engage in the labor force to financially support their parents (downward bias) or quit working to provide them with informal care (upward bias). Furthermore, if young women stop working to take care of their parents, their experience and opportunity cost of continuing in the labor force would decrease.

On the other hand, young mothers might also have to quit the labor force if they experience a severe illness themselves that requires childcare help from grandparents or in-laws, which would underestimate the effect of grandparental childcare use on mother's labor force participation.

Finally, FE can suffer from reverse causality bias if for example after retirement, grandparents experience a decrease in income jointly with an increase in leisure allowing them to take care of their grandchildren. Thus, mothers might engage in the labor force to support their parents financially regardless of grandparental childcare availability, which would overestimate the effects of grandparent's childcare on mother's labor force participation. Unfortunately, the NLSY79 does not provide information of grandparent's labor force participation and income.

Our second approach is to employ IV methods, which account for both timeinvariant ${ }^{6}$ heterogeneity and reverse causality. To predict changes in grandparental childcare, we use a dummy variable that takes a value of one if the maternal grandmother has passed away. Our instrument solves one set of problems but introduces others: IV estimates will still be biased if the death of maternal grandmother changes a young woman's labor force participation through channels other than the availability of grandparental childcare ${ }^{7}$.

For example, maternal grandmothers might take care of both their grandchildren and their spouses so that when grandmothers pass away, young women might have to take care of their fathers. If they engage in the labor force to pay for formal elderly care, IV estimates will underestimate the effect of grandparental childcare on mother's labor force participation, while if they resign from their jobs to take care of their fathers themselves, IV estimates will be upward biased.

IV estimates will be also problematic if the maternal grandmother was taking care of her grandchildren right before falling sick and passing away. Thus, daughters might have to either quit their jobs to provide informal care to their own mothers (downward bias) or to join the labor force to support them financially (upward bias).

In Section 6 we exploit information on young women's and their parent's health status to explore the aforementioned threats to our identification strategies.

\section{Data}

The National Longitudinal Survey of Youth 1979 (NLSY79) consists of a nationally representative panel of 12,686 men and women between the ages of 14 and 21 who were first interviewed in 1979. The NLSY79 collects rich information on employment, education, background characteristics, and a proxy for ability, the AFQT. Individuals were surveyed annually from 1979 until 1994 and bi-annually afterwards.

Beginning in 1986, 11,420 children of the 6,283 female NLSY79 respondents have been interviewed bi-annually forming the Children of the NLSY79 (CNLSY79) sample. Questions on childcare form the Mother Supplement of the CNLSY79 and it is included in both the NLSY79 and the CNLSY79. This survey includes a battery of 
retrospective questions about childcare arrangements that are updated in each wave for every child between 0-3 years of age born to a female respondent of the NLSY79 ${ }^{8}$. Mothers are asked about the primary, secondary, and tertiary childcare arrangements for each and every biological child. In particular, the childcare question reads: "Other than yourself, what is your primary/secondary/tertiary child care arrangement?" The possible answers are: other parent, sibling, grandparent ${ }^{9}$, other relative, non-relative, day care, nursery, or preschool. Our explanatory variable of interest splits the sample into mothers whose children have a grandparent as their primary, secondary, or tertiary childcare provider during that particular year and those who do not ${ }^{10}$.

The longitudinal feature of the NLSY79 allows us to merge the aforementioned retrospective childcare information of children between $0-3$ years of age to characteristics and labor force participation of mothers at the time their children where $0-3$. Thus, we restrict the sample to women in their prime fertility age range (18 to 49 ) interviewed between 1979 and 2006 for whom we have information on (i) childcare arrangements, (ii) whether their mothers (maternal grandmothers in this paper) where alive when the child was $0-3$ and the year when they passed away, and (iii) the set of family background characteristics depicted in Tables 1 and $2^{11}$.

To instrument grandparental childcare we use a dummy equal to one if the maternal grandmother is dead in year $t$. We construct the instrument using a set of retrospective questions asked in the Health Supplement when women turn 40 that includes information on whether the grandmother is alive and the age at which she passed away ${ }^{12}$.

Tables 1 and 2 show family characteristics by type of childcare and maternal grandmother's status, respectively. We can see in Table 1 that, as suspected, there exist significant differences in means between almost all characteristics of young women who rely on grandparents to mind their children and their counterparts. This preliminary analysis supports the suspicion that individual heterogeneity might play an important role in biasing OLS estimates of the effect of grandparents' childcare on young women's labor force participation and that FE estimates might be more reliable than OLS. However, a priori, it does not seem straightforward to pin down the sign of the bias because the differences in means associated with socio-economic characteristics do not always point in the same direction. While young women who rely on their parents or in-laws for childcare are more likely to belong to a minority, be a single mother, have lower scores on the AFQT, have less income and not live in a household in which someone owned a library card when they were 14 years old, they are also more likely to participate in the labor force, less likely to be teenage mothers and more likely to have attended college than those who rely on other type of childcare.

Table 2 splits the sample between young women whose mothers are deceased and their counterparts to provide some insight into whether our instrument might be plausibly exogenous. If there are significant differences between groups in observable characteristics that are likely to be correlated with further unobservable variables associated with the labor force participation of young women, then the IV estimates will also be problematic. While there are less significant differences between groups in Table 2 than in Table 1, we can still see some disparities between groups. In particular, young women with living mothers score significantly higher on the AFQT, are more likely to be married, are less likely to be black, and are younger than young women with 
Table 1 Background characteristics by type of childcare

\begin{tabular}{|c|c|c|c|}
\hline & $\begin{array}{l}\text { Grandparents' } \\
\text { childcare }\end{array}$ & $\begin{array}{l}\text { No grandparents' } \\
\text { childcare }\end{array}$ & $\begin{array}{l}\text { Differences in } \\
\text { means }\end{array}$ \\
\hline \multirow[t]{2}{*}{ Maternal labor force participation (MLFP) } & 0.82 & 0.56 & $0.27^{* * *}$ \\
\hline & $(0.38)$ & $(0.50)$ & \\
\hline \multirow[t]{2}{*}{ AFQT } & 0.17 & 0.26 & $-0.09 * * *$ \\
\hline & $(0.94)$ & $(1.00)$ & \\
\hline \multirow[t]{2}{*}{ Black } & 0.19 & 0.15 & $0.04^{* * *}$ \\
\hline & $(0.39)$ & $(0.36)$ & \\
\hline \multirow[t]{2}{*}{ Hispanic } & 0.09 & 0.07 & $0.02^{* * *}$ \\
\hline & $(0.28)$ & $(0.25)$ & \\
\hline \multirow[t]{2}{*}{ Less than high school } & 0.13 & 0.15 & $-0.03^{* * *}$ \\
\hline & $(0.33)$ & $(0.36)$ & \\
\hline \multirow[t]{2}{*}{ High school graduate } & 0.48 & 0.46 & 0.02 \\
\hline & $(0.50)$ & $(0.50)$ & \\
\hline \multirow[t]{2}{*}{ Some college } & 0.26 & 0.20 & $0.06^{* * *}$ \\
\hline & $(0.44)$ & $(0.40)$ & \\
\hline \multirow[t]{2}{*}{ College graduate } & 0.05 & 0.05 & -0.01 \\
\hline & $(0.21)$ & $(0.23)$ & \\
\hline \multirow[t]{2}{*}{ Age } & 26.14 & 27.11 & $-0.97^{* * *}$ \\
\hline & $(4.95)$ & $(5.37)$ & \\
\hline \multirow[t]{2}{*}{ Married } & 0.75 & 0.78 & $-0.03^{* * *}$ \\
\hline & $(0.43)$ & $(0.41)$ & \\
\hline \multirow[t]{2}{*}{ Never married } & 0.17 & 0.14 & $0.03^{* * *}$ \\
\hline & $(0.37)$ & $(0.34)$ & \\
\hline \multirow[t]{2}{*}{ Single mother } & 0.25 & 0.22 & $0.03^{* * *}$ \\
\hline & $(0.43)$ & $(0.41)$ & \\
\hline \multirow[t]{2}{*}{ Teenage mother } & 0.28 & 0.31 & -0.03 \\
\hline & $(0.45)$ & $(0.46)$ & \\
\hline \multirow[t]{2}{*}{ Number of children in the household } & 1.40 & 1.68 & $-0.27^{* * *}$ \\
\hline & $(0.95)$ & $(1.09)$ & \\
\hline \multirow[t]{2}{*}{ Household income not including mother's } & 37,218 & 47,056 & $-9,838^{* * *}$ \\
\hline & (93) & $(120)$ & \\
\hline \multirow[t]{2}{*}{ Lives in a SMSA } & 0.73 & 0.77 & $-0.04^{* * *}$ \\
\hline & $(0.44)$ & $(0.42)$ & \\
\hline \multirow[t]{2}{*}{ Lived in a SMSA in 1979} & 0.68 & 0.70 & $-0.03^{* *}$ \\
\hline & $(0.47)$ & $(0.46)$ & \\
\hline \multirow[t]{2}{*}{ Any HH had a library card when mother was 14} & 0.72 & 0.77 & $-0.05^{* * *}$ \\
\hline & $(0.45)$ & $(0.42)$ & \\
\hline Observations & 1,910 & 12,749 & 14,659 \\
\hline
\end{tabular}

Weighted means to account for oversampling of minorities. Standard deviations (s.d.) in parentheses. ${ }^{* * *} p<0.01$, ${ }^{* *} p<0.05,{ }^{*} p<0.1$.

AFQT is age-standardized with mean 0 and s.d. of 1. Household income in real dollars (base year 1983).

$\mathrm{HH}$ stands for household member and SMSA for Standard Metropolitan Statistical Area.

$M L F P=1$ if the respondent participates in the labor force (employed or unemployed). 
Table 2 Background characteristics by grandmother's death

\begin{tabular}{|c|c|c|c|}
\hline & $\begin{array}{l}\text { Grandmother } \\
\text { alive }\end{array}$ & $\begin{array}{l}\text { Grandmother } \\
\text { deceased }\end{array}$ & $\begin{array}{l}\text { Differences in } \\
\text { means }\end{array}$ \\
\hline \multirow[t]{2}{*}{ Maternal labor force participation (MLFP) } & 0.59 & 0.56 & $0.03^{* *}$ \\
\hline & $(0.49)$ & $(0.50)$ & \\
\hline \multirow[t]{2}{*}{ AFQT } & 0.26 & 0.09 & $0.17^{* * *}$ \\
\hline & $(0.99)$ & $(1.03)$ & \\
\hline \multirow[t]{2}{*}{ Black } & 0.15 & 0.24 & $0.09^{* * *}$ \\
\hline & $(0.36)$ & $(0.43)$ & \\
\hline \multirow[t]{2}{*}{ Hispanic } & 0.07 & 0.06 & 0.01 \\
\hline & $(0.26)$ & $(0.24)$ & \\
\hline \multirow[t]{2}{*}{ Less than high school } & 0.15 & 0.17 & $-0.02^{*}$ \\
\hline & $(0.35)$ & $(0.38)$ & \\
\hline \multirow[t]{2}{*}{ High school graduate } & 0.47 & 0.45 & 0.01 \\
\hline & $(0.50)$ & $(0.50)$ & \\
\hline \multirow[t]{2}{*}{ Some college } & 0.21 & 0.21 & 0.00 \\
\hline & $(0.41)$ & $(0.40)$ & \\
\hline \multirow[t]{2}{*}{ College graduate } & 0.05 & 0.05 & 0.00 \\
\hline & $(0.22)$ & $(0.22)$ & \\
\hline \multirow[t]{2}{*}{ Age } & 26.89 & 28.37 & $-1.47^{* * *}$ \\
\hline & $(5.32)$ & $(5.33)$ & \\
\hline \multirow[t]{2}{*}{ Married } & 0.78 & 0.71 & $0.07^{* * *}$ \\
\hline & $(0.41)$ & $(0.45)$ & \\
\hline \multirow[t]{2}{*}{ Never married } & 0.13 & 0.20 & $-0.07^{* * *}$ \\
\hline & $(0.34)$ & $(0.40)$ & \\
\hline \multirow[t]{2}{*}{ Single mother } & 0.22 & 0.29 & $-0.07^{* * *}$ \\
\hline & $(0.41)$ & $(0.45)$ & \\
\hline \multirow[t]{2}{*}{ Teenage mother } & 0.31 & 0.32 & -0.01 \\
\hline & $(0.46)$ & $(0.47)$ & \\
\hline \multirow[t]{2}{*}{ Number of children in the household } & 1.63 & 1.89 & $-0.27^{* * *}$ \\
\hline & $(1.07)$ & $(1.19)$ & \\
\hline \multirow[t]{2}{*}{ Household income not including mother's } & 46,004 & 44,366 & 1,638 \\
\hline & (118) & $(107)$ & \\
\hline \multirow[t]{2}{*}{ Lives in a SMSA } & 0.76 & 0.73 & $0.03^{* *}$ \\
\hline & $(0.43)$ & $(0.44)$ & \\
\hline \multirow[t]{2}{*}{ Lived in SMSA in 1979} & 0.70 & 0.67 & $0.03^{*}$ \\
\hline & $(0.46)$ & $(0.47)$ & \\
\hline \multirow[t]{2}{*}{ Any HH had a library card when mother was 14} & 0.76 & 0.73 & $-0.02^{* *}$ \\
\hline & $(0.42)$ & $(0.44)$ & \\
\hline Observations & 13,521 & 1,138 & 14,659 \\
\hline
\end{tabular}

Weighted means to account for oversampling of minorities. Standard deviations (s.d.) in parentheses. ${ }^{* *} p<0.01$, ${ }^{* *} p<0.05,{ }^{*} p<0.1$.

AFQT is age-standardized with mean 0 and s.d. of 1. Household income in real dollars (base year 1983).

$\mathrm{HH}$ stands for household member and SMSA for Standard Metropolitan Statistical Area.

$M L F P=1$ if the respondent participates in the labor force (employed or unemployed). 
deceased mothers. As expected, young women with deceased mothers are also older than their counterparts because they are also more likely to have older parents.

Although we include this rich set of variables in our IV model together with survey year and regional controls, we cannot dismiss the possibility that we might be omitting a relevant variable both related to maternal grandmother's death and young women's labor force participation. For example, while we do proxy for cognitive ability using the AFQT, we do not have a measure of non-cognitive ability. If young women's labor force participation and the likelihood of having a grandmother alive are positively correlated with non-cognitive ability, IV will overestimate the true effect of grandparental childcare on young women's labor force participation.

\section{Results}

Table 3 presents the results for OLS, FE and IV in columns (1), (2), and (3), respectively. OLS estimates suggest that when grandparents take care of grandchildren, young mothers are almost 16 percentage points more likely to participate in the labor force. For the most part, the remaining regression coefficients are as expected. Age and its square have a positive and negative sign, respectively, capturing a concave functional form of the effect of age on mother's labor force participation and the higher the educational attainment, the greater the likelihood of participating in the labor force (omitted category is "less than high school").

Next, we compare OLS with FE and IV estimates. We can see that when accounting for family heterogeneity in FE models, young mothers' likelihood of participating in the labor force significantly increases by 9 percentage points on average ${ }^{13}$. Thus, OLS seems to overestimate the effect of grandparental childcare on mother's labor force participation, which is consistent with the existence of significant differences in characteristics seen in Table 1.

In the last column, we use an indicator variable for whether the maternal grandmother is alive as an instrument for grandparental childcare (GPC in the estimating equation). This choice is based on the fact that we only have information on maternal grandparents because the NLSY79 only follows mothers, and that there is some evidence that maternal grandmothers are more likely to take care of grandchildren than any other grandparent ${ }^{14}$.

Unfortunately IV produces imprecise estimates and they are very similar in magnitude to OLS. On the one hand, IV estimates are still interesting because they take into account both reverse causality, as well as individual heterogeneity. On the other hand, we have seen in Table 2 that families with deceased maternal grandmothers seem to be more disadvantaged than their counterparts. Even though we are able to control for a large set of background characteristics in our specifications, if we are still omitting variables that explain maternal grandparental death and young women's labor force participation, IV estimates are likely to be biased. While the direction of the bias in OLS is unclear, IV estimates are likely to overestimate the effect of grandparental childcare on young women's labor force participation because women from a disadvantaged background are less likely to work (Olivetti and Petrongolo, 2008) and seem more likely to have a deceased mother (Table 2).

Thus, our preferred estimates are FE because they are more precise than IV, account for family heterogeneity and are the most conservative estimate of the effect of grandparents' childcare on young women's labor force participation. 
Table 3 Effect of grandparents' childcare on MLFP

\begin{tabular}{|c|c|c|c|}
\hline \multirow[t]{2}{*}{ Dependent variable: MLFP } & OLS & $\mathrm{FE}$ & IV \\
\hline & (1) & (2) & (3) \\
\hline \multirow[t]{2}{*}{ Grandparents' childcare } & $0.159^{* * *}$ & $0.090^{* * *}$ & 0.146 \\
\hline & $(0.011)$ & $(0.014)$ & $(0.292)$ \\
\hline \multirow[t]{2}{*}{ AFQT } & $0.030^{* * *}$ & & $0.030^{* * *}$ \\
\hline & $(0.007)$ & & $(0.008)$ \\
\hline \multirow[t]{2}{*}{ Age } & $0.039^{* * *}$ & $0.084^{* * *}$ & $0.039^{* * *}$ \\
\hline & $(0.013)$ & $(0.018)$ & $(0.013)$ \\
\hline \multirow[t]{2}{*}{ Age squared } & $-0.001^{* * *}$ & $-0.001^{* * *}$ & $-0.001^{* * *}$ \\
\hline & $(0.000)$ & $(0.000)$ & $(0.000)$ \\
\hline \multirow[t]{2}{*}{ Number of children } & $-0.036^{* * *}$ & $-0.050^{* * *}$ & $-0.036^{* * *}$ \\
\hline & $(0.005)$ & $(0.006)$ & $(0.006)$ \\
\hline \multirow[t]{2}{*}{ Black } & $0.074^{* * *}$ & & $0.074^{* * *}$ \\
\hline & $(0.014)$ & & $(0.015)$ \\
\hline \multirow[t]{2}{*}{ Hispanic } & 0.013 & & 0.013 \\
\hline & $(0.014)$ & & $(0.018)$ \\
\hline \multirow[t]{2}{*}{ High school graduate } & $0.039^{* * *}$ & -0.028 & $0.039^{* *}$ \\
\hline & $(0.013)$ & $(0.025)$ & $(0.015)$ \\
\hline \multirow[t]{2}{*}{ Some college } & $0.052^{* * *}$ & -0.037 & $0.053^{* *}$ \\
\hline & $(0.017)$ & $(0.033)$ & $(0.023)$ \\
\hline \multirow[t]{2}{*}{ College graduate } & 0.030 & 0.011 & 0.030 \\
\hline & $(0.028)$ & $(0.050)$ & $(0.028)$ \\
\hline \multirow[t]{2}{*}{ Married } & 0.007 & -0.018 & 0.007 \\
\hline & $(0.018)$ & $(0.017)$ & $(0.019)$ \\
\hline \multirow[t]{2}{*}{ Never married } & -0.008 & 0.024 & -0.008 \\
\hline & $(0.019)$ & $(0.025)$ & $(0.019)$ \\
\hline \multirow[t]{2}{*}{ Teenage mother } & 0.004 & & 0.004 \\
\hline & $(0.015)$ & & $(0.015)$ \\
\hline \multirow[t]{2}{*}{ Lives in a SMSA } & 0.024 & -0.019 & 0.023 \\
\hline & $(0.015)$ & $(0.018)$ & $(0.016)$ \\
\hline \multirow[t]{2}{*}{ Log (Household income not including mother's) } & $-0.016^{* * *}$ & $-0.015^{* * *}$ & $-0.016^{* * *}$ \\
\hline & $(0.005)$ & $(0.005)$ & $(0.006)$ \\
\hline \multirow[t]{2}{*}{ Lived in a SMSA in 1979} & -0.008 & & -0.008 \\
\hline & $(0.015)$ & & $(0.015)$ \\
\hline \multirow[t]{2}{*}{ Any HH member had a library card when mother was 14} & 0.005 & & 0.004 \\
\hline & $(0.013)$ & & $(0.014)$ \\
\hline \multirow[t]{2}{*}{ Constant } & 0.133 & -0.332 & 0.134 \\
\hline & $(0.171)$ & $(0.290)$ & $(0.183)$ \\
\hline Observations & 14,659 & 14,659 & 14,659 \\
\hline \multicolumn{2}{|l|}{ Number groups in FE model } & 3,158 & \\
\hline
\end{tabular}

Weighted estimates account for oversampling of minorities. Clustered standard errors at the family level in parentheses.

${ }^{* * *} \mathrm{p}<0.01,{ }^{* *} \mathrm{p}<0.05,{ }^{*} \mathrm{p}<0.1$. HH stands for household member and SMSA for Standard Metropolitan Statistical Area.

Omitted category of education is "less than high school." MLFP=1 if the respondent participates in the labor force.

AFQT is age-standardized with mean 0 and s.d. of 1 . All include region and survey year dummies.

The instrument of grandparent's childcare is $=1$ if the maternal grandmother has passed away.

All include a dummy for mothers with missing $\mathrm{HH}$ income information. Income in 1983 dollars. 
The magnitude of the effect that we find is larger than the average found in the formal childcare literature. For example, Gelbach (2002) uses quarter of birth as an instrument for public school enrollment of 5-year olds and finds that enrollment increases mother's labor force participation by 5 percentage points. A more recent example is Fitzpatrick (2012), who uses child's age eligibility for public school enrollment in a regression discontinuity framework to show that school enrollment increases mothers' labor force participation only for single mothers by 15 to 20 percentage points.

We expected, however, to find a larger effect in our case because the mothers included in our sample have children who are still not eligible to attend school and are therefore in greater need of childcare than older children. In addition, we cannot fully compare our estimates with the formal care literature because our larger effect may be also due to the intrinsic nature of this type of childcare, which might not only substitute for but also complement formal childcare. In fact, the availability of grandparental childcare may be particularly crucial for women who work full time and/or have long commutes to work and thus need long childcare hours or for those women with children who frequently fall sick and are not allowed to attend a formal childcare facility when feeling unwell to avoid contagion to other children.

Finally, it is somewhat reassuring that the magnitude of our effect is consistent with the closest study to ours by Compton and Pollak (2013) who use family proximity as an instrument for grandparent's childcare availability.

\subsection{Heterogeneous effects}

If we think of grandparent's availability as a childcare subsidy, reducing the cost of childcare (increasing grandparental availability in our case) should have a greater impact on labor force participation of young mothers who are likely to be constrained by prices of formal childcare ${ }^{15}$. To further test this hypothesis, we divide the sample by background characteristics of young mothers in Table 4. We can see that indeed, the magnitude of FE coefficient estimates is larger than the baseline estimates from Table 3 for minorities, young women who are single or have never been married, and young mothers whose parents where separated by the time they were 14 years old. Nonetheless, the effect is surprisingly smaller for teenage mothers and not significantly higher for women who live in a poor household. It is important to note, however, that female labor force participation is, on average, 26 percentage points higher in poor households than in wealthier households.

Hence, these results support the claim that the effects found for our preferred specification (FE) are likely to be causal ${ }^{16}$.

\section{Robustness checks}

In this section we exploit the richness of the NLSY79 data to investigate some of the potential threats to our identifying assumptions discussed in Section 3. Note that the first three columns in the top panel of Table 5 replicate our baseline model from Table 3.

\subsection{Grandparents' health status}

In Section 3, we argued that if grandparents stop taking care of grandchildren because their health status deteriorates, young women could either engage in the labor force to 
Table 4 Heterogeneous effect of grandparents' childcare on maternal labor force participation (MLFP)

\begin{tabular}{|c|c|c|c|c|c|c|c|c|}
\hline \multirow[t]{2}{*}{ Subsample } & \multicolumn{6}{|c|}{ Dependent variable: MLFP } & \multirow{2}{*}{$\begin{array}{l}\text { Number of } \\
\text { observations }\end{array}$} & \multirow{2}{*}{$\begin{array}{l}\text { Average } \\
\text { MLFP }\end{array}$} \\
\hline & $\begin{array}{l}\text { OLS } \\
\text { Coefficient }\end{array}$ & s.e. & $\begin{array}{l}\text { FE } \\
\text { Coefficient }\end{array}$ & s.e. & $\begin{array}{l}\text { IV } \\
\text { Coefficient }\end{array}$ & s.e. & & \\
\hline Black & $0.134^{* * *}$ & $(0.018)$ & $0.092^{* * *}$ & $(0.024)$ & 0.042 & $(0.325)$ & 4,456 & 0.57 \\
\hline Hispanic & $0.158^{* * *}$ & $(0.023)$ & $0.139^{* * *}$ & $(0.029)$ & 0.361 & $(0.381)$ & 3,069 & 0.52 \\
\hline Non-black & $0.165^{* * *}$ & $(0.013)$ & $0.091^{* * *}$ & $(0.016)$ & 0.207 & $(0.397)$ & 10,203 & 0.57 \\
\hline Never married & $0.104^{* * *}$ & $(0.028)$ & $0.098^{* * *}$ & $(0.031)$ & 0.247 & $(0.341)$ & 3,392 & 0.48 \\
\hline Married & $0.170^{* * *}$ & $(0.013)$ & $0.087^{* * *}$ & $(0.017)$ & 0.096 & $(0.458)$ & 9,879 & 0.60 \\
\hline Single mother & $0.117^{* * *}$ & $(0.023)$ & $0.092^{* * *}$ & $(0.026)$ & 0.139 & $(0.278)$ & 4,778 & 0.50 \\
\hline Teen mother & $0.176^{* * *}$ & $(0.025)$ & $0.074^{* * *}$ & $(0.023)$ & 1.125 & $(0.728)$ & 5,768 & 0.47 \\
\hline $\begin{array}{l}\text { Non-teenage } \\
\text { mother }\end{array}$ & $0.153^{* * *}$ & $(0.013)$ & $0.096^{* * *}$ & $(0.017)$ & -0.165 & $(0.324)$ & 8,891 & 0.64 \\
\hline Poor household & $0.142^{* * *}$ & $(0.032)$ & $0.090^{* *}$ & $(0.036)$ & 0.120 & $(0.468)$ & 3,838 & 0.38 \\
\hline $\begin{array}{l}\text { Non-poor } \\
\text { household }\end{array}$ & $0.151^{* * *}$ & $(0.012)$ & $0.090^{* * *}$ & $(0.016)$ & 0.058 & $(0.391)$ & 10,204 & 0.64 \\
\hline $\begin{array}{l}\text { Separated maternal } \\
\text { grandparents }\end{array}$ & $0.173^{* * *}$ & $(0.019)$ & $0.109^{* * *}$ & $(0.023)$ & 0.229 & $(0.510)$ & 5,963 & 0.60 \\
\hline $\begin{array}{l}\text { Not separated } \\
\text { maternal } \\
\text { grandparents }\end{array}$ & $0.147^{* * *}$ & $(0.014)$ & $0.076^{* * *}$ & $(0.017)$ & -0.001 & $(0.323)$ & 8,344 & 0.53 \\
\hline
\end{tabular}

Clustered standard errors at the family level in parentheses. ${ }^{* *} p<0.01,{ }^{* *} p<0.05,{ }^{*} p<0.1$.

MLFP $=11$ if the respondent participates in the labor force (employed or unemployed). The instrument of grandparent's childcare is $=1$ if the maternal grandmother has passed away.

All estimates include, age, age squared, education, living in an urban area, log (household income not including

mother's), number of children, and region and survey year dummies. OLS and IV estimates include AFQT, race, lived in an urban area in 1979 and living in a household with a library card owner at age 14.

Poor household is a variable included in the NLSY79 that follows the U.S. Department of Health and Human

Services guidelines.

All include a dummy for missing $\mathrm{HH}$ income information except from the poor/non-poor subsamples.

financially support their elders or quit working to provide them with informal care, downward or upward biasing FE estimates, respectively. Similarly, if a grandparent's illness precedes their death, IV estimates are problematic because young mothers might have to change their labor force participation status to help out regardless of grandparental childcare availability. Although the NLSY79 does not directly provide information about grandparents' health status and only contains survey questions on maternal grandparents, we indirectly test this hypothesis in several ways.

First, we use the year before death of a maternal grandmother or grandfather as proxies for suffering a severe illness before passing away. We can see in the last three columns of the middle panel of Table 4 that the magnitude and the significance of our coefficients of interest is indistinguishable from our baseline specification when we include a dummy equal to one in the year before the maternal grandmother passes away. The first three columns of the bottom panel include an analogous dummy for the year previous to maternal grandfather's death. In this case, our preferred FE estimates are still significant and large but have slightly decreased from 0.09 to 0.08 . Similarly, OLS estimates drop slightly and IV estimates, although insignificant, reverse their sign to negative. Thus, there seems to be some mild evidence that young women might provide their fathers with informal care before their fathers pass away.

We also argued that if young women stop working to take care of their remaining relatives, their experience and opportunity cost of continuing in the labor force would 
Table 5 Robustness checks

\begin{tabular}{|c|c|c|c|c|c|c|}
\hline Dependent variable: MLFP & $\begin{array}{l}\text { OLS } \\
\text { (1) }\end{array}$ & $\begin{array}{l}\mathrm{FE} \\
(2)\end{array}$ & $\begin{array}{l}\text { IV } \\
\text { (3) }\end{array}$ & $\begin{array}{l}\text { OLS } \\
\text { (4) }\end{array}$ & $\begin{array}{l}\mathrm{FE} \\
(5)\end{array}$ & $\begin{array}{l}\text { IV } \\
\text { (6) }\end{array}$ \\
\hline \multirow[t]{2}{*}{ Grandparent's childcare } & $0.159^{* * *}$ & $0.090^{* * *}$ & 0.146 & $0.143^{* * *}$ & $0.080^{* * *}$ & -0.158 \\
\hline & $(0.011)$ & $(0.014)$ & $(0.292)$ & $(0.012)$ & $(0.017)$ & $(0.258)$ \\
\hline \multirow[t]{2}{*}{ Experience since leaving school } & & & & $0.044^{* * *}$ & -0.000 & $0.049^{* * *}$ \\
\hline & & & & $(0.004)$ & $(0.007)$ & $(0.006)$ \\
\hline \multirow[t]{2}{*}{ Experience squared } & & & & $-0.001^{* * *}$ & $-0.001^{* *}$ & $-0.001^{* * *}$ \\
\hline & & & & $(0.000)$ & $(0.000)$ & $(0.000)$ \\
\hline Observations & 14,659 & 14,659 & 14,659 & 12,851 & 12,851 & 12,850 \\
\hline Number of families in FE models & & 3,158 & & & 2,743 & \\
\hline \multirow[t]{2}{*}{ Grandparent's childcare } & $0.151^{* * *}$ & $0.089^{* * *}$ & 0.006 & $0.159^{* * *}$ & $0.089^{* * *}$ & 0.156 \\
\hline & $(0.023)$ & $(0.032)$ & $(0.413)$ & $(0.011)$ & $(0.014)$ & $(0.292)$ \\
\hline \multirow{2}{*}{$\begin{array}{l}\text { Health problem prevents } \\
\text { mother from working }\end{array}$} & $-0.152^{* * *}$ & $-0.159^{* * *}$ & $-0.154^{* * *}$ & & & \\
\hline & $(0.013)$ & $(0.016)$ & $(0.014)$ & & & \\
\hline \multirow{2}{*}{$\begin{array}{l}\text { Year before maternal grandmother } \\
\text { passed away }\end{array}$} & & & & -0.064 & -0.054 & -0.064 \\
\hline & & & & $(0.042)$ & $(0.039)$ & $(0.041)$ \\
\hline Observations & 7,505 & 7,505 & 7,501 & 14,659 & 14,659 & 14,659 \\
\hline Number of families in FE models & & 2,341 & & & 3,158 & \\
\hline \multirow[t]{2}{*}{ Grandparent's childcare } & $0.155^{* * *}$ & $0.081^{* * *}$ & -0.054 & $0.154^{* * *}$ & $0.081^{* * *}$ & -0.061 \\
\hline & $(0.013)$ & $(0.015)$ & $(0.336)$ & $(0.013)$ & $(0.017)$ & $(0.339)$ \\
\hline \multirow{2}{*}{$\begin{array}{l}\text { Year before maternal grandfather } \\
\text { passed away }\end{array}$} & 0.025 & $0.063^{*}$ & 0.029 & & & \\
\hline & $(0.036)$ & $(0.032)$ & $(0.037)$ & & & \\
\hline \multirow{2}{*}{$\begin{array}{l}\text { Age maternal grandfather when } \\
\text { daughter was born }\end{array}$} & -0.000 & & 0.000 & 0.001 & & 0.001 \\
\hline & $(0.001)$ & & $(0.001)$ & $(0.002)$ & & $(0.002)$ \\
\hline \multirow[t]{2}{*}{ Maternal grandfather alive } & & & & 0.049 & 0.117 & 0.051 \\
\hline & & & & $(0.067)$ & $(0.166)$ & $(0.068)$ \\
\hline \multirow{2}{*}{$\begin{array}{l}\text { Age maternal grandfather interacted with } \\
\text { maternal grandfather alive }\end{array}$} & & & & -0.001 & -0.002 & -0.000 \\
\hline & & & & $(0.002)$ & $(0.005)$ & $(0.002)$ \\
\hline Observations & 13,382 & 13,382 & 13,382 & 13,382 & 13,382 & 13,382 \\
\hline Number of families in FE models & & 2,950 & & & 2,950 & \\
\hline
\end{tabular}

Weighted estimates to account for oversampling of minorities. Clustered standard errors at the family level in parentheses.

*** $p<0.01,{ }^{* *} p<0.05, * p<0.1$. All include marital status, education, living in a SMSA, log(household income not including mother's),

number of children, and region and survey year dummies. MLFP=1 if the respondent participates in the labor force. OLS models include AFQT, race, lived in a SMSA in 1979, teenage mother, and living in a household with a library card owner at age 14 .

All include a dummy for mothers with missing income information.

All include age and age squared except from the specifications including experience and experience squared.

The instrument of grandparent's childcare is $=1$ if the maternal grandmother has passed away.

decrease. To test this possibility, we also include actual work experience and its square in the baseline specification. As we can see in the last three columns of the top panel of Table 5, estimates are very similar to the ones including the year before the maternal grandfather passes away, which is again consistent with the possibility that young women are quitting the labor force earlier than expected to provide informal care to their elders.

Finally, in the last three columns in the bottom panel of Table 5 we include how old the maternal grandfather was when he had his daughter and its interaction with having 
a maternal grandmother alive ${ }^{17}$. We should expect that the older is the father when the grandmother passes away, the more likely it is that he needs help from his daughter. Quite surprisingly, the magnitude of the effect is the same as in the last two additional robustness checks.

Hence, while it seems that the need of informal care for maternal grandfathers might indirectly affect our estimates, our results are robust to the inclusion of health status proxies.

\subsection{Young mother's health status}

We also argued in Section 3 that young mothers might have to quit the labor force if they experience a severe illness themselves. If these women require childcare help from grandparents or in-laws, FE models will underestimate the effect of grandparental childcare availability on mother's labor force participation. The first three columns of the mid panel of Table 5 show that when we include a variable that it is equal to one if the respondent has any health problem that prevents her from working, the estimates are not significantly different from the ones in our baseline specification $^{18}$.

\subsection{Maternal grandmother's status and mother's labor force participation before birth}

We have already argued that there might be further reasons other than grandparents taking care of children that might make young women decide to stop working when grandmothers pass away and we have discussed how such a situation might bias our IV estimates.

We now address this main concern with a different approach. If having a deceased grandparent affects mother's labor force participation in ways other than the availability of childcare, it should also affect mother's labor force participation before the birth of the child. For example, young women whose mothers pass away might be emotionally unstable and therefore less able to engage in the labor force. We test this hypothesis by including observations for the period just prior to giving birth to their first child in our model of maternal labor force participation. Results are shown in Table 6. As we can see, while we do find some evidence that having a maternal grandmother passing away before giving birth is associated with a decrease in young women's labor force participation, the estimate is not significantly different from $0^{19}$.

\section{Discussion}

We use a range of identification strategies to confirm previous findings that grandparental childcare availability is a significant determinant of mother's labor force participation. After comparing OLS with FE and IV estimates and discussing the validity of the identifying assumptions, we conclude that in the U.S., grandparent's childcare availability significantly increases mother's labor force participation by at least 9 percentage points. We also show that women from disadvantaged socio-economic backgrounds (Black, Hispanic and single or never married) are the most likely to be encouraged to participate in the labor force when they receive help from their parents, which is consistent with the evidence that grandparental childcare is more affordable than formal childcare (Presser, 1989). 
Table 6 Maternal labor force participation before childbearing

\begin{tabular}{|c|c|}
\hline & OLS \\
\hline \multirow[t]{2}{*}{ Grandmother dead } & -0.041 \\
\hline & $(0.035)$ \\
\hline \multirow[t]{2}{*}{ AFQT } & 0.012 \\
\hline & $(0.009)$ \\
\hline \multirow[t]{2}{*}{ Age } & -0.001 \\
\hline & $(0.018)$ \\
\hline \multirow[t]{2}{*}{ Age squared } & -0.000 \\
\hline & $(0.000)$ \\
\hline \multirow[t]{2}{*}{ Number of children } & $-0.049^{* * *}$ \\
\hline & $(0.011)$ \\
\hline \multirow[t]{2}{*}{ Black } & 0.010 \\
\hline & $(0.021)$ \\
\hline \multirow[t]{2}{*}{ Hispanic } & -0.012 \\
\hline & $(0.021)$ \\
\hline \multirow[t]{2}{*}{ High school graduate } & $0.034^{*}$ \\
\hline & $(0.018)$ \\
\hline \multirow[t]{2}{*}{ Some college } & $0.043^{* *}$ \\
\hline & $(0.020)$ \\
\hline \multirow[t]{2}{*}{ College graduate } & 0.016 \\
\hline & $(0.025)$ \\
\hline \multirow[t]{2}{*}{ Married } & -0.040 \\
\hline & $(0.024)$ \\
\hline \multirow[t]{2}{*}{ Never married } & $-0.046^{*}$ \\
\hline & $(0.025)$ \\
\hline \multirow[t]{2}{*}{ Teenage mother } & -0.025 \\
\hline & $(0.022)$ \\
\hline \multirow[t]{2}{*}{ Lives in a Standard Metropolitan Statistical Area } & $0.052^{* *}$ \\
\hline & $(0.022)$ \\
\hline \multirow[t]{2}{*}{ Log (Household income not including mother's) } & -0.001 \\
\hline & $(0.007)$ \\
\hline \multirow[t]{2}{*}{ Lived in a Standard Metropolitan Statistical Area in 1979} & -0.008 \\
\hline & $(0.018)$ \\
\hline \multirow[t]{2}{*}{ Any household member had a library card when mother was 14} & -0.009 \\
\hline & $(0.016)$ \\
\hline \multirow[t]{2}{*}{ Constant } & $0.836^{* * *}$ \\
\hline & $(0.249)$ \\
\hline Observations & 3,120 \\
\hline
\end{tabular}

Weighted estimates to account for oversampling of minorities. ${ }^{* * *} p<0.01,{ }^{* *} p<0.05,{ }^{*} p<0.1$.

Robust standard errors in parentheses. Includes region and survey year dummies.

$M L F P=1$ if the respondent participates in the labor force (employed or unemployed).

Omitted category of education is "less than high school". Income in 1983 dollars.

Includes a dummy for mothers with missing income information.

AFQT is age-standardized with mean 0 and s.d. of 1 .

Our findings shed light on the possibility that governments actively pursuing policies aiming to increase retirement ages might have been ignoring a possible trade-off between young and older women's labor force participation through grandparental 
childcare availability. Future research should also consider whether childcare subsidies might crowd out the use of grandparents for childcare and to what extent subsidies can potentially affect outcomes of disadvantaged children.

\section{Endnotes}

${ }^{1}$ Female labor force participation increased from $43 \%$ in 1970 to $58.1 \%$ in 2011 (U.S. Bureau of Labor Statistics 2013).

${ }^{2}$ Some examples of literature on subsidized childcare and mother's labor force participation are Fitzpatrick (2012, 2010), Cascio (2009), Baker et al. (2008), and Gelbach (2002).

${ }^{3}$ Instituto Nacional de Estadistica, 2005. Note that European references do not exclude other childcare arrangements and therefore are not directly comparable with Figure 1.

${ }^{4}$ For a review of the earliest literature see Guzman (1999).

${ }^{5}$ The magnitude and the significance of the coefficients do not change in unweighted models. Results available upon request.

${ }^{6}$ While Fixed Effect Instrumental Variables (FEIV) estimates account for both endogeneity and time-varying heterogeneity, coefficients are even more imprecisely estimated than IV and are therefore uninformative. Results available upon request.

${ }^{7}$ In addition to satisfying the exogeneity assumption, our instrument should be strongly and negatively correlated with our instrumented variable. We should also expect the effect of grandmothers' death on MLFP to be negative. Additional file 1: Table S2 in the Appendix shows the first stage of the IV and the reduced-form model of the direct impact of maternal grandmother's death on MLFP in columns (1) and (2), respectively. Reassuringly, Column (1) shows that having a deceased grandmother is strongly and negatively correlated with MLFP and Column (2) depicts a negative correlation between grandmothers' death and MLFP.

${ }^{8}$ The only year the CNLSY79 did not collect information on childcare was 1990, but the information was updated through the retrospective questions in 1992 and the upcoming waves for those women who did not take the Mother Supplement in 1992.

${ }^{9}$ While we can distinguish between grandparents who take care of grandchildren in the child or grandparent's home, results do not depend on this distinction and are available upon request.

${ }^{10}$ Using whether grandparents are only the primary or primary or secondary childcare arrangement, does not alter the results. Results available upon request.

${ }^{11}$ Additional file 1: Table S1 in the Appendix shows selected characteristics of respondents by survey year.

${ }^{12}$ The information is combined with the year of birth of grandmothers collected in a supplement survey module in 1987 and 1988.

${ }^{13}$ Both the p-value of a test of joint significance of individual effects and a Hausman test of the appropriateness of $\mathrm{FE}$ are less than 0.01 .

${ }^{14}$ Neither the NLSY79 nor the Survey of Income and Program Participation (SIPP) provide information about which grandparent is taking care of the child. However, using SHARE we find that grandchildren are mostly cared for by maternal grandmothers, followed by maternal grandfathers, paternal grandmothers and paternal grandfathers.

${ }^{15}$ While in theory grandparental childcare could have a negative income effect on hours worked, we focus on the extensive margin (labor force participation) and 
therefore, for non-working women, cheaper or free childcare raises the net wage and labor force participation.

${ }^{16}$ Although unlikely, the pattern of biases from time-varying heterogeneity or reverse causality could coincidentally produce a similar pattern.

${ }^{17}$ We cannot include contemporaneous maternal grandparental age because we do not have that variable for deceased grandfathers and it is highly correlated with the age of the maternal grandmother.

${ }^{18}$ Results in Table 5 are not driven by the reduction in sample size when introducing additional controls. In all models, the estimates of grandparent's childcare of the reduced sample without the additional controls are not statistically different from the ones presented in Table 3. Results available upon request.

${ }^{19}$ The OLS estimate if we restrict the sample to all the years before giving birth to the first child is even closer to zero and insignificant. Results available upon request.

\section{Additional file}

Additional file 1: Table S1. Selected Sample Characteristics by Year. Table S2. IV First Stage and OLS Reduced Form.

\section{Competing interests}

The IZA Journal of Labor Policy is committed to the IZA Guiding Principles of Research Integrity. The authors declare that they have observed these principles.

\section{Acknowledgements}

Thanks to Kevin Lang, Daniele Paserman, Denzil Fiebig, Robert A. Margo, Sara de la Rica, Tess Stafford, Anna Zhu, the editor and two anonymous referees for excellent suggestions. Thanks to participants at the COSME session of the SAEe meetings in Zaragoza.

Responsible editor: David Neumark

\section{Author details}

${ }^{1}$ The World Bank, 1818 H Street, NW, Washington, DC 20433, USA. ²University of New South Wales and IZA, ASB building, 2052, Sydney, Australia.

Received: 7 March 2013 Accepted: 18 September 2013

Published: 10 Oct 2013

\section{References}

Albuquerque P, Passos J (2010) Grandparents and Women Participation in the Labor Market. Working Paper No.16/ 2010/DE/SOCIUS/CEMAPRE, School of Economics and Management, Technical University of Lisbon

Baker M, Gruber J, Milligan K (2008) Universal Child Care, Maternal Labor Supply and Family Well-being. Journal of Political Economy 116(4):709-745

Bien W, Riedel B, Rauschenbach T (2006) Wer betreutet Deutscher Kinder? Cornelser Verlag

Cascio E (2009) Maternal Labor Supply and the Introduction of Kindergartens into American Public Schools. Journal of Human Resources 44(1):140-170

Coe NB, Van Houtven CH (2009) Caring for Mom and Neglecting Yourself? the Health Effects of Caring for an Elderly Parent eds. Health Economics 18(9):991-1010

Compton J, Pollak RA (2013) Family Proximity, Childcare, and Women's Labor Force Attachment. Journal of Urban Economics. in press

Del Boca D (2002) The effect of child care and part time opportunities on participation and fertility decisions in Italy. Journal of Population Economics 15:549-573

Del Boca D, Locatelli M, Vuri D (2005) Child-Care Choices by Working Mothers: The Case of Italy. Review of Economics of the Household 3(4):453-477

Farré L, Vella F (2013) The Intergenerational Transmission of Gender Role Attitudes and its Implications for Female Labour Force Participation. Economica 80(318):219-247

Fitzpatrick MD (2010) Preschoolers Enrolled and Mothers at Work: The Effects of Universal Prekindergarten. Journal of Labor Economics 28(1):51-85

Fitzpatrick MD (2012) Revising Our Thinking About the Relationship Between Maternal Labor Supply and Preschool. Journal of Human Resources 47(3):538-612

García-Morán E, Kuehn Z (2012) With strings attached: grandparent-provided child care, fertility, and female labor market outcomes. CEPRA Working Paper

Gelbach J (2002) Public Schooling for Young Children and Maternal Labor Supply. American Economic Review 92 (1):307-22 
Guzman $L$ (1999) The use of grandparents as child care providers. Center for Demography and Ecology, University of Wisconsin-Madison. NSFH Working Paper 84

Instituto Nacional de Estadística (2005) Conciliación entre la vida laboral y la familiar., Módulo de la Encuesta de Población Activa

Lang K, Zagorsky JL (2001) Does Growing Up With a Parent Absent Really Hurt? Journal of Human Resources 34(2):253-273

Leibowitz A, Klerman JA, Waite LJ (1992) Employment of New Mothers and Child Care Choice. Journal of Human Resources 27(1):112-133

Maurer-Fazio M, Conelly R, Chen L, Tang L (2011) Childcare, Eldercare, and Labor Force Participation of Married Women in Urban China, 1982-2000. Journal of Human Resources 46(2):261-294

Mosisa A, Hipple S (2006) Trends in Labor Force Participation in the United States. Monthly Labor Review 129(10):35-57

Mulligan C, Rubinstein Y (2008) Selection, Investment, and Women's Relative Wages over Time. Quarterly Journal of Economics 123(3):1061-1110

Olivetti C, Petrongolo B (2008) Unequal Pay or Unequal Employment? A Cross-country Analysis of Gender Wage Gaps. Journal of Labor Economics 26(4):621-654

Presser BH (1989) Some Complexities of Child Care Provided by Grandmothers. Journal of Marriage and the Family 51:581-591

Smith K (2000) Who's Minding the Kids? Child Care Arrangements, Fall 1995. , US

Smith K (2002) Who's Minding the Kids? Child Care Arrangements, Spring 1997. , US

Zamarro G (2011) Family Labor Participation and Child Care Decisions. The Role of Grannies, RAND Working Paper WR-833

10.1186/2193-9004-2-14

Cite this article as: Posadas and Vidal-Fernandez: Grandparents' Childcare and Female Labor Force Participation.

IZA Journal of Labor Policy 2013, 2:14

Submit your manuscript to a SpringerOpen ${ }^{\circ}$ journal and benefit from:

- Convenient online submission

- Rigorous peer review

- Immediate publication on acceptance

- Open access: articles freely available online

- High visibility within the field

- Retaining the copyright to your article

Submit your next manuscript at $\gg$ springeropen.com 